\title{
ASSESSMENT OF PREHEATING AND SONIC OSCILLATION OF BULK-FILL RESIN COMPOSITE ON MARGINAL ADAPTATION OF CLASS II RESTORATIONS
}

\author{
Asmaa M. Abdallah*, Tamer M. El-shehawy*, Noha A. El-Wassefy** and Marmar A. Montaser*
}

\begin{abstract}
Objectives: To assess the influence of preheating and sonic oscillation of bulk-fill composite on marginal adaptation of class II restorations.

Materials and methods: 30 extracted molars were collected, and standardized compound class II cavities were prepared. Teeth were classified into three groups $(n=10)$ according to placement techniques. Group I, the composite material was placed in bulk to fill the prepared cavity using a plastic filling instrument. Group II, composite syringes were placed in the Therma-Flo device before placement into the cavities. Group III, the composite material was placed in bulk to fill the prepared cavity using a plastic filling instrument then adapted by compothixo oscillating packing instrument. After finishing and polishing, the specimens were subjected to thermocycling. Marginal analysis was carried out using Scanning Electron Microscope at $500 \mathrm{x}$ magnifications. The overall margins were investigated, and the maximum gaps were measured.
\end{abstract}

Results: Although preheated composite produce better marginal adaptation, there was no significant difference between all tested groups.

Conclusion None of the placement techniques produced gap-free margins. Preheated composite improved marginal adaptation

KEYWORDS Bulk-fill composite, preheating composite, sonic fill composite, compothixo and marginal adaptation.

\section{INTRODUCTION}

Utilization of resin-based composite (RBC) for restoration of posterior teeth become a daily routine in dental clinics as a result of their conservation of tooth structure, adhesion to dental tissues, and esthetics. In spite of the improvement of RBC materials, composite restorations may not be totally successful due to inadequate polymerization, wear, and microleakage, which may also produce postoperative sensitivity and recurrent caries ${ }^{1}$.

* Lecturer, Operative Dentistry Department, Faculty of Dentistry, Mansoura University, Egypt.

** Professor Assistant, Dental Biomaterials Department, Faculty of Dentistry, Mansoura University, Egypt. 
Continuous research to improve handling and clinical performance of resin composite had led to excellent results. "Bulk-Fill" dental composite was introduced to the dental market to simplify the clinical restorative procedures as it can be placed and light-cured in a 4 to $5 \mathrm{~mm}$ thickness single increment, reducing the risk of incorporating air bubbles between the increments or contamination ${ }^{2}$. It was reported to have lower polymerization shrinkage and stresses than do traditional RBCs. The increase of filler loads and viscosity of these materials give them a packable consistency that improves handling properties by increasing sculptability, and improves mechanical properties ${ }^{3}$.

Bulk-fill composite can be used in stress-bearing posterior areas and provide adequate contacts which can produce perfect class II restorations. Packable RBCs with high viscosity have shown some problems related to cavity wall adaptation and voids, especially at the gingival portion of Class II restorations ${ }^{4,5}$. The marginal adaptation is defined as the degree of proximity of a restoration to a tooth surface. The quality and durability of the marginal integrity has great effect on esthetics and longevity of composite restorations ${ }^{6}$. Poor marginal adaptation will eventually lead to microleakage and marginal staining, postoperative sensitivity, and recurrent caries. The formation of a marginal gap may also lead to pain on biting and adhesive failure after repeated occlusal loading ${ }^{7}$.

Many factors can affect the quality of marginal adaptation of bonded composite restorations such as material properties, cavity design and operative techniques. The technique of insertion and adaptation of composites needs improvement, to avoid the formation of gaps. Several possible strategies do exist to achieve good cavity adaptation by reducing the composite viscosity. Ideally, materials should adapt and flow into every corner of the cavity but not flow after removing the applied force ${ }^{8}$. The availability of low elasticity liners as glass ionomer and flowable resins facilitates its use as the first increment under composite restorations. Experiments on the effect of these materials on marginal adaptation has shown varied results ranging from promising results ${ }^{9}$ to no effect ${ }^{10}$ at all and may lead to drop in marginal adaptation and increase microleakage ${ }^{11}$. Which led to controversy between researchers. Studies showed Improved results have attributed to lower material viscosity, better wettability of the cavity walls ${ }^{9}$. Also, formation of stress breaker layer during polymerization ${ }^{12}$. Unfortunately, physical properties were deteriorated due to reduction in viscosity which done by decrease filler content of the material ${ }^{13}$.

Preheating of RBCs has been advocated as a method to improve marginal adaptation, degree of conversion and increase composite flow. The increase in degree of conversion depends on many factors as decreases RBC viscosity, increased temperature, and enhances the mobility of free radicals, resulting in higher degree of conversion ${ }^{14}$ . Pre-heating bulk-fill composites is an interesting way to reduce viscosity temporarily comparable to that of flowable composites without deterioration of mechanical properties of highly filled RBC ${ }^{15}$.

Preheating units are used to preheat the composite before application to a temperature range from $37^{\circ} \mathrm{c}$ to $68^{\circ} \mathrm{c}$. After composite preheating viscosity of the material decreases temporarily to be similar to that of flowable composite ${ }^{16}$. This preheated material can be used on the gingival floor of the cavity gaining the advantage of low viscosity producing better wetting of cavity walls. Studies showed increased flowability and better handling characteristics of preheated resins without dropping of their physical properties ${ }^{17}$. Also, it was found that there is a correlation between temperature and degree of conversion of resin composite . Preheated composite requires less light exposure for better polymerization $^{18}$. 
Viscosity can also be reduced using sonic osscilation, thus allowing better adaptation of the highly filled RBC into the cavity walls ${ }^{19,20}$. Sonic driven resin composite insertion is one of the new methods to reduce the effect of shrinkage stresses on the tooth restoration interface. The sonic system enable clinicians to place posterior resin composite restorations that combine the advantages of flowable composite with a universal composite. The manufacturer's claimed that Smart vibrations produced from this device give the composite material good adaptation, superior reduction of voids, precise application, and layer thickness control ${ }^{21}$.

This study aimed to assess the influence of preheating of Bulk-fill RBC and ultrasonic application on marginal adaptation of class II composite restoration. The null hypothesis was that there is no difference in marginal adaptation among different groups.

\section{MATERIALS AND METHODS}

\section{Materials}

Two materials were employed in this study. A Bulk-fill resin-based composites; Filtek Bulk-Fill Posterior Restorative (3M ESPE st.Paule, MN, USA), and the adhesive system was Single Bond Universal (3M ESPE st.Paule, MN, USA)

\section{Methods}

\section{Teeth selection and specimen preparation}

Thirty sound human molars free of caries or restorations were collected. The collected teeth were ultrasonically cleaned with an ultrasonic scaler (XH-E412 ultrasonic cleaner, xinghua Ltd, china) to clean the adherend soft tissues, then stored in $0.5 \%$ chloramine- $\mathrm{T}$ solution at room temperature for $24 \mathrm{~h}$ for disinfection. To ensure that the teeth are crack-free, the teeth were examined under stereomicroscope (SZ-PT, Olympus, Tokyo, Japan) at 30- $\times$ magnification. The teeth were stored in physiologic saline at $37^{\circ} \mathrm{C}$ to avoid accumulation of bacteria or fungi ${ }^{22}$.

\section{Mounting of teeth}

Root surface of each tooth was covered by a thin layer of wax from apex up to $2 \mathrm{~mm}$ from CEJ. The teeth were fixed in polyvinyl chloride tube $(3 \mathrm{~cm}$ length - 0.5-inch width) by acrylic resin material. The teeth were removed from the tube after resin polymerization by dipping in hot water bath. Polyether impression material (Impregum, ESPE, Seefeld, Germany) was inserted into acrylic resin before teeth repositioning in the tubes. After setting of the impression material, the excess was removed by sharp scalpel ${ }^{23}$.

\section{Cavity preparation and grouping of samples}

A high-speed hand piece (NSK panaAir FX, Japan) mounted on especially designed Jig was used to prepare a standardized slot class II occlusomesial cavity in each tooth. The cavity dimensions were $3 \mathrm{~mm}$ width bucco-lingually, $4 \mathrm{~mm}$ depth pulpally with no axial wall. A carbide bur (\# 245, SS White;Meta Dental Com, Korea) was used for cavity preparation and was changed every five cavities. There was no occlusal conversion in the cavity and the cavo-surface angle was butt-joint.

All specimens were assorted into 3 different groups according to the various technique of placement $(n=10)$ as follows: Group I; teeth were restored with resin composite using hand instruments. Group II; teeth were restored with resin composite after heating to $60^{\circ} \mathrm{C}$ using Therma-Flo (Vista Dental Products, Wisconsin, USA). Group III; teeth were restored with resin composite using Compothixo (Compothixo KerrHawe SA-Via Strecce 4-6934 Bioggio/Switzerland).

\section{Restorative procedures}

A Tofflemire matrix band was contoured and applied around the teeth. Each tooth was bonded by 
Single Bond Universal using etch-and-rinse mode according to manufacturer instructions. Phosphoric acid was applied to enamel margin then dentin for $15 \mathrm{~s}$ then washed by copious amount of water and air dried. Bonding agent was applied to the cavity surface by micro-brush with agitation for 10 s then air dried for $5 \mathrm{~s}$, finally light-cured by light emitting diode device at an intensity of $1000 \mathrm{mw} / \mathrm{cm} 2$ (Elipar Deep Cure; 3 M ESPE) and the intensity was monitored by radiometer (Demetron LC, Kerr, Germany).

After bonding, restoration of teeth was done as follow. For group I; cavities were filled in bulk with bulk-fill resin composite using plastic instruments then light cured for $20 \mathrm{~s}$. For group II; composite syringe was placed in the Therma-Flo device before cavities filling. The heated composite was inserted in one increment to fill the prepared cavity by a plastic instrument, then light cured for $20 \mathrm{~s}$. For group III; composite was placed in the same way of that of group I then composite was adapted using compothixo oscillating packing instrument, then light cured for $20 \mathrm{~s}$.

Each restoration was finished and polished using Enhance polishing kit (DENTSPLY-Sirona, USA). The teeth were ultrasonically cleaned to get rid of any polishing remnants before thermocycling for 1000 time (Nova, Konya, Turkey).

\section{Marginal integrity test}

All specimens were gold sputtered, all cavity margins were examined by Scanning Electron Microscope at $500 \times$ magnifications. The maximum gaps were measured, marginal integrity was scored as follow:

- $\quad$ Score 0: zero marginal gap.

- $\quad$ Score 1: marginal gap $<30 \mu \mathrm{m}$.

- $\quad$ Score 2: marginal gap $>30 \mu \mathrm{m}$.

\section{Statistical Analysis}

Statistical package for Social Science (SPSS Inc, Chicago, IL, US) was used for analysis of the collected data.

\section{RESULTS}

The overall marginal adaptation scores of all groups are shown in Table 1, Figure. 1, and representative scanning electron photomicrographs are shown in Figure. 2. The scores are compared by Kruscal-Wallis statistical test and was not statistically significant ( $p=0.767$ ). Mann Whitney was used to compare between the marginal adaptation of Bulkfill and Pre-heating groups and found not statistically significant $(p=0.569)$. Same Statistical procedure was used to compare between Sonic and pre-heating groups and found not statistically significant ( $p=$ $0.796)$ and also found not statistically significant between Bulk-fill and Sonic groups $(\mathrm{p}=0.739)$

TABLE (1): Proportion of samples showing marginal adaptation of all tested groups.

\begin{tabular}{|c|c|c|c|}
\hline $\begin{array}{c}\text { Marginal adaptation } \\
\text { scores }\end{array}$ & Bulkfill & Preheating & Sonic \\
\hline 0 & 0 & 2 & 1 \\
\hline 1 & 7 & 6 & 7 \\
\hline 2 & 3 & 2 & 2 \\
\hline
\end{tabular}

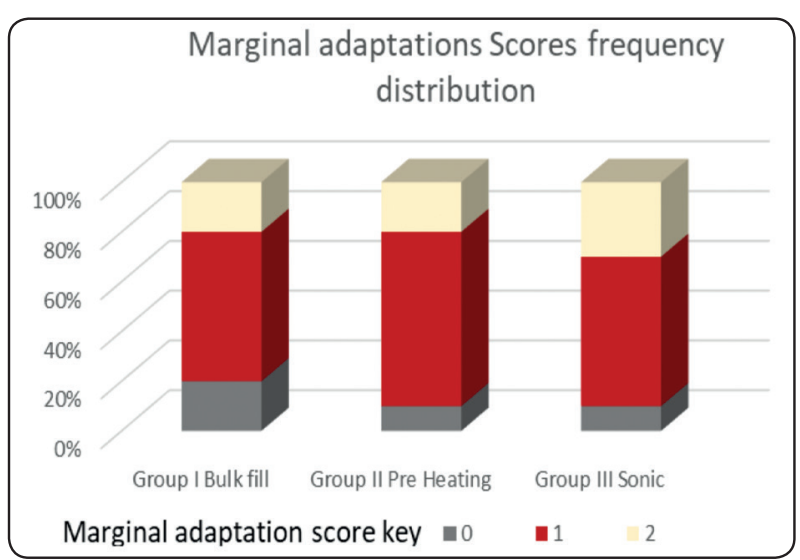

Fig. (1) Marginal adaptation scores 


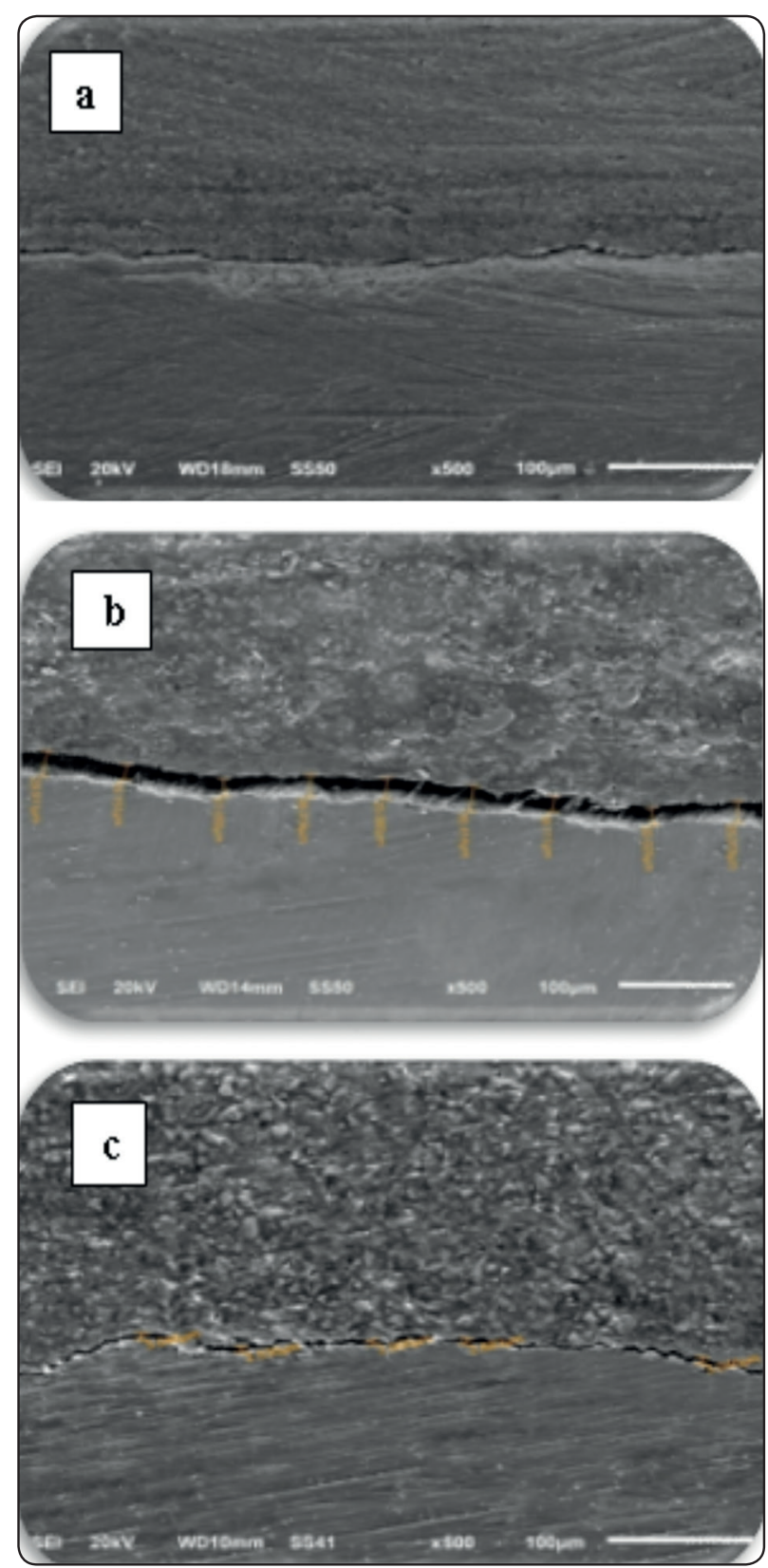

Fig. (2) Representative SEM micrographs at $500 \mathrm{X}$ magnifications. (a); continuous margins of specimens restored with preheated Filtek Bulk-Fill Posterior Restorative composite. (b); non-continuous margins of specimens restored with Filtek Bulk-Fill Posterior Restorative composite. (c); non-continuous margins of specimens restored with Filtek Bulk-Fill Posterior Restorative composite after application with Compothixo.

\section{DISCUSSION}

Marginal adaptation is a very important factor affecting the restoration prognosis ${ }^{24}$. Improved placement technique of RBC, composite formulation and curing technique can minimize polymerization shrinkage stresses ${ }^{25}$. The marginal seal at tooth-restoration interface can be measured by either marginal adaptation measurements or micro-leakage measurements. Marginal adaptation was chosen for this study to provide a quantitative analysis of the amount and width of gaps formed at the margins and marginal irregularities rather than the qualitative isolated analysis provided by microleakage. Quantitative marginal analysis was introduced by Porte, Lutz et al. ${ }^{26}$ and was later refined by Blunck and Roulet ${ }^{27}$. This refined method of recording of marginal gaps was selected for the current study to decrease subjectivity and to measure the width and number of gaps for statistical comparisons between different placement techniques ${ }^{27}$.

Butt-joint, clean-cut non-beveled preparation in the occlusal cavities was preferred in this study, because beveled cavo-surface outline preparation results in a thin margin of composite resin which may fracture, leaving a ledge-type defect at the marginal region ${ }^{28}$. Examination of marginal adaptation between different specimens was performed using scanning electron microscope (SEM) at a magnification of 500x in order to view the entire cavity margin and to confirm accuracy of preparation and polishing of the restorations.

The direct scanning of tooth structure was preferred because indirect epoxy resin replicas showed some drawbacks compared to direct one. Fabrication of resin replica was time consuming, and some specimens had voids or excess epoxy resin. Furthermore, it is difficult to determine the extent to which the structures will be changed after preparation process ${ }^{24}$. Then images were taken using a magnification of $500 \times$. This magnification was necessary to discriminate between the different 
gap criteria and was chosen based on other studies which have examined the external marginal adaptation of different dental restorations under the same magnification of $500 \times{ }^{29}$.

The present laboratory study evaluated marginal adaptation with a bulk-fill posterior resin-based composite after placed with bulk-fill, preheating and sonic driven resin composite application device. The hypothesis that there are no significant differences in marginal adaptation between the methods of application of resin composite restorative materials. It was stated that it's not realistically achievable to get a $100 \%$ gap free margins ${ }^{30}$. Slight differences in the marginal gaps between groups (non-significant differences) were observed.

In this study, preheated bulk-fill was used in the form of syringes. When a composite is heated up to $60^{\circ} \mathrm{C}$ and removed from the device, its temperature decreases $35-40 \%$ after $40 \mathrm{~s}^{31}$. The heating unit was placed very close to the cavity to be restored to allow quick application and to allow the minimum amount of heat to be dissipated during manipulation. This comes in agreement with Daronch et al. ${ }^{32}$ In 2006 as many authors suggested to work with the composite quickly to avoid rapid decrease in temperature for best clinical performance ${ }^{33}$.

In the current study, the packing instrument that condenses the material by vibration was used to pack resin composite. This technique assumes that vibration decreases the viscosity of the resin, so the material flow and adapt to the cavity walls in like flowable composite ${ }^{20}$.

In the current study, preheating of the filtek bulk-fill composite resin (Group II) presented better marginal adaptation compared to both the same bulkfill composite that was placed using the compothixo packing instrument (Group III) and the bulkfill method. This could be explained that increasing the composite temperature, decreases the viscosity of the materials and enhance molecular mobility as a result of higher thermal energy, resulting in additional polymerization. This improves the placement and adaptation of the material within the cavity walls ${ }^{34}$.

The results of the current study were in agreement with Taraboanta et al. ${ }^{35}$, who found that preheating of resin-based materials improves the adaptation of these materials to tooth structures. In contrast to our results, Elsayad ${ }^{36}$, found that marginal adaptation will not enhanced by preheating resin composite to $68^{\circ} \mathrm{C}$. It was concluded that a rapid polymerization occurred by increasing the temperature. This rapid reaction leads to increase polymerization stress that may lead to cuspal deflection or debonding of the restoration.

The results of the current study were in agreement with with Karaarslan et al. ${ }^{37}$, who found no significant differences among the preheated groups (Composite preheated to $37^{\circ} \mathrm{C}, 54^{\circ} \mathrm{C}$ and $68^{\circ} \mathrm{C}$ ). In addition, Deb $\mathrm{S}$ et al. ${ }^{38}$, found that although marginal adaptation may be better because of the enhanced flowability of preheated resin composites, shrinkage may also be greater because of higher monomer conversion. They highlighted that increased shrinkage may counteract the improved adaptation achieved by warming composites, leading to no difference in microleakage of composites cured under different temperature conditions (The flow properties and microleakage were evaluated at $22{ }^{\circ} \mathrm{C}$ and $\left.60{ }^{\circ} \mathrm{C}\right) . .^{37,38}$

In Group III, compothixo oscillation makes the material more adherent to the instrument and more difficult to apply due to the high viscosity of bulkfill material leading to the poor adaptation between restoration and cavity walls. A variety of studies have shown that lower viscosity of composites can improve adaptation and reduce microleakage ${ }^{20,34}$. In contrast to our results, Eunice et al ${ }^{39}$, evaluated the marginal microleakage with SonicFill ${ }^{\mathrm{TM}}$. Their study showed that the high oscillation energy had no effect concerning the microleakage of packable composite resin, where no statistically significant 
difference was found between the incremental and oscillation packing methods used in their study, it was found that the polymerization shrinkage is similar in both methods.

\section{CONCLUSION}

The null hypotheses of the study were accepted. It can be stated that none of the placement techniques produced gap-free margins. Preheated composite improved marginal adaptation compared to bulk and sonic placement technique.

\section{REFERENCES}

1. Misilli U, Yılmaz F. Evaluation of marginal microleakage in composite restorations with different placement techniques. Int Dent Res 2018;8(2):70-77.

2. Margeas RCJCoceid. Bulk-fill materials: simplify restorations, reduce chairtime. Compend Contin Educ Dent 2015;36(1):e1-4.

3. El-Damanhoury H, Platt JJOd. Polymerization shrinkage stress kinetics and related properties of bulk-fill resin composites. Oper Dent. 2014;39(4):374-382.

4. Darabi F, Tayefeh-Davalloo R, Tavangar SM, Naser-Alavi F, Boorboo-Shirazi M. The effect of composite resin preheating on marginal adaptation of class II restorations. J Clin Exp Dent. 2020;12(7):e682-e687.

5. Pereira R, Lima DANL, Giorgi MCC, Marchi GM, Aguiar FHB. Evaluation of bond strength, nanoleakage, and marginal adaptation of Bulk-fill composites submitted to thermomechanical aging. J Adhes Dent 2019;21(3):255-264.

6. Boroujeni PM, Mousavinasab SM, Hasanli EJJoi, dentistry c. Effect of configuration factor on gap formation in hybrid composite resin, low-shrinkage composite resin and resin-modified glass ionomer. J Investig Clin Dent. 2015;6(2):156-160.

7. Kim RJY, Kim YJ, Choi NS, Lee IB. Polymerization shrinkage, modulus, and shrinkage stress related to toothrestoration interfacial debonding in bulk-fill composites. J Dent $2015 ; 43: 430-439$.

8. Ramic BD, Premovic MT, Stojanac IL, Drobac MR, Petrovic LM. Improved marginal adaptation of composite restorations by using different placement and light polymerization techniques. Am J Dent 2018;31(1):7-12.
9. Karaman E, Ozgunaltay G. Polymerization shrinkage of different types of composite resins and microleakage with and without liner in class II cavities. Oper Dent. 2014;39:325-331.

10. Banomyong D, Harnirattisai C, Burrow MF. Posterior resin composite restorations with or without resin-modified, glass-ionomer cement lining: A 1-year randomized, clinical trial. J Investig Clin Dent. 2011;2:63-69.

11. Lohbauer U, Zinelis S, Rahiotis C, Petschelt A, Eliades $\mathrm{G}$. The effect of resin composite pre-heating on monomer conversion and polymerization shrinkage. Dent Mater. 2009;25:514-19.

12. Aggarwal V, Singla M, Yadav S, Yadav H. Effect of flowable composite liner and glass ionomer liner on class II gingival marginal adaptation of direct composite restorations with different bonding strategies J Dent 2014;42(5):619-625.

13. Rodríguez HA, Kriven WM, Casanova H. Development of mechanical properties in dental resin composite: Effect of filler size and filler aggregation state Mater Sci Eng C Mater Biol Appl 2019;101:274-282.

14. Demirel G, Orhan AI, Irmak O, Aydın F, Büyüksungur A, Bilecenoğlu B, Orhan K.. Effects of Preheating and Sonic Delivery Techniques on the Internal Adaptation of Bulkfill Resin Composites. Oper Dent. 2021 ;46(2):226-233.

15. Alshali RZ, Salim NA, Satterthwaite JD, Silikas NJJod. Post-irradiation hardness development, chemical softening, and thermal stability of bulk-fill and conventional resin-composites. J Dent. 2015;43(2):209-218.

16. Deb S, Di Silvio L, Mackler HE, \& Millar BJ. Pre-warming of dental composites Dental Materials 2011;27(4): e51-e59.

17. Lucey S, Lynch CD, Ray NJ, Burke FM, \& Hannigan A. Effect of pre-heating on the viscosity and microhardness of a resin composite. J Oral Rehabil 2010; 37(4): 278-282.

18. Tauböck TT, Tarle Z, Marovic D, Attin T. Pre-heating of high-viscosity bulk-fill resin composites: Effects on shrinkage force and monomer conversion. J Dent. 2015;43(11):1358-1364.

19. Cantoro A, Goracci C, Coniglio I, Magni E, Polimeni A, Ferrari M. Influence of ultrasound application on inlays luting with self-adhesive resin cements. Clin Oral Investig. 2011;15(5):617-623.

20. Iovan G, Stoleriu S, Moldovanu A, Morogai S, Andrian SJIJMD. SEM study of the interface between the cavity wall and composite resin in cavities filled using vibration. Int J Med Dent. 2011;1(3):254-258. 
21. The scientific profile of Sonic -driven composite packing device www.kerrdental.com/en-no/dental-restorationproducts/compothixo.

22. Scotti N, Comba A, Gambino A, et al. Microleakage at enamel and dentin margins with a bulk fills flowable resin. Eur J Dent. 2014;8(1):1-8.

23. Assiri A, Alomairy A, Magdy N. Marginal Adaptation of Bulk-Fill versus Layered Resin Composite Restorations. International Journal of Health Sciences \& Research 2018; 8(6): 65-74.

24. Garcia D, Yaman P, Dennison J, Neiva G. Polymerization shrinkage and depth of cure of bulk fill flowable composite resins. Oper Dent 2014;39:441-448.

25. Gamarra VSS, Borges GA, Júnior LHB, Spohr AM. Marginal adaptation and microleakage of a bulk-fill composite resin photopolymerized with different techniques 2018;106(1):56-63.

26. Porte A, Lutz F, Lund MR, Swartz ML, Cochran MA. Cavity designs for composite resins. Oper Dent. 1984; 9(2):50-56.

27. Blunck U, Roulet JF. In vitro marginal quality of dentinbonded composite resins in Class V cavities. Quintessence Int. 1989; 20(6):407-412.

28. Campos EA, Ardu S, Lefever D, Jassé FF, Bortolotto T, Krejci I. Marginal adaptation of class II cavities restored with bulk-fill composites. J Dent. 2014;42(5):575-581.

29. Furness A, Tadros MY, Looney SW, Rueggeberg FA. Effect of bulk/incremental fill on internal gap formation of bulk-fill composites. J Dent. 2014;42(4):439-449.

30. Blunck U, Zaslansky P. Enamel margin integrity of Class I one-bottle all-in-one adhesives-based restorations. J Adhes Dent. 2011;13(1):23-29.
31. Arslan S, Demirbuga S, Zorba YO, Ucar FI, Tuncay OJEJoGD. The effect of pre-heating silorane and methacrylatebased composites on microleakage of class $\mathrm{V}$ restorations. Eur J gene Dent. 2012;1(3):178.

32. Daronch M, Rueggeberg FA, De Goes MF, Giudici R. Polymerization kinetics of pre-heated composite. J Dent Res. 2006;85(1):38-43.

33. Zhao S, Qian Y, Liu H, Jiang L, Zhou L. The effect of preheating on light cured resin composites. J Hard Tissue Biol. 2012;21:273-278.

34. Alizadeh Oskoee P, Pournaghi Azar F, Jafari Navimipour E, Ebrahimi Chaharom ME, Naser Alavi F, Salari A. The effect of repeated preheating of dimethacrylate and silorane-based composite resins on marginal gap of class V restorations. J Dent Res Dent Clin Dent Prospects. 2017;11(1):36-42.

35. Taraboanta I, Stoleriu S, Iovan G, et al. Evaluation of preheating effects on marginal adaptation of resin-based materials. J Mater Plast. 2018;55(2):238-242.

36. Elsayad I. Cuspal movement and gap formation in premolars restored with preheated resin composite. Oper Dent. 2009; 34(6):725-731

37. Karaarslan ES, Usumez A, Ozturk B, Cebe MA. Effect of cavity preparation techniques and different preheating procedures on microleakage of class V resin restorations. Eur J Dent. 2012;6(1):87-94.

38. Deb S, Di Silvio L, Mackler HE, Millar BJ. Pre-warming of dental composites. Dent Mater. 2011;27(4):e51-59.

39. Eunice C, Margarida A, Joao C, Filomena B, Anabela P, Pedro AJAivemJS. Evaluation of microleakage of composite resin restorations with SonicFill. J Stomatol. 2012;2:1-9. 